
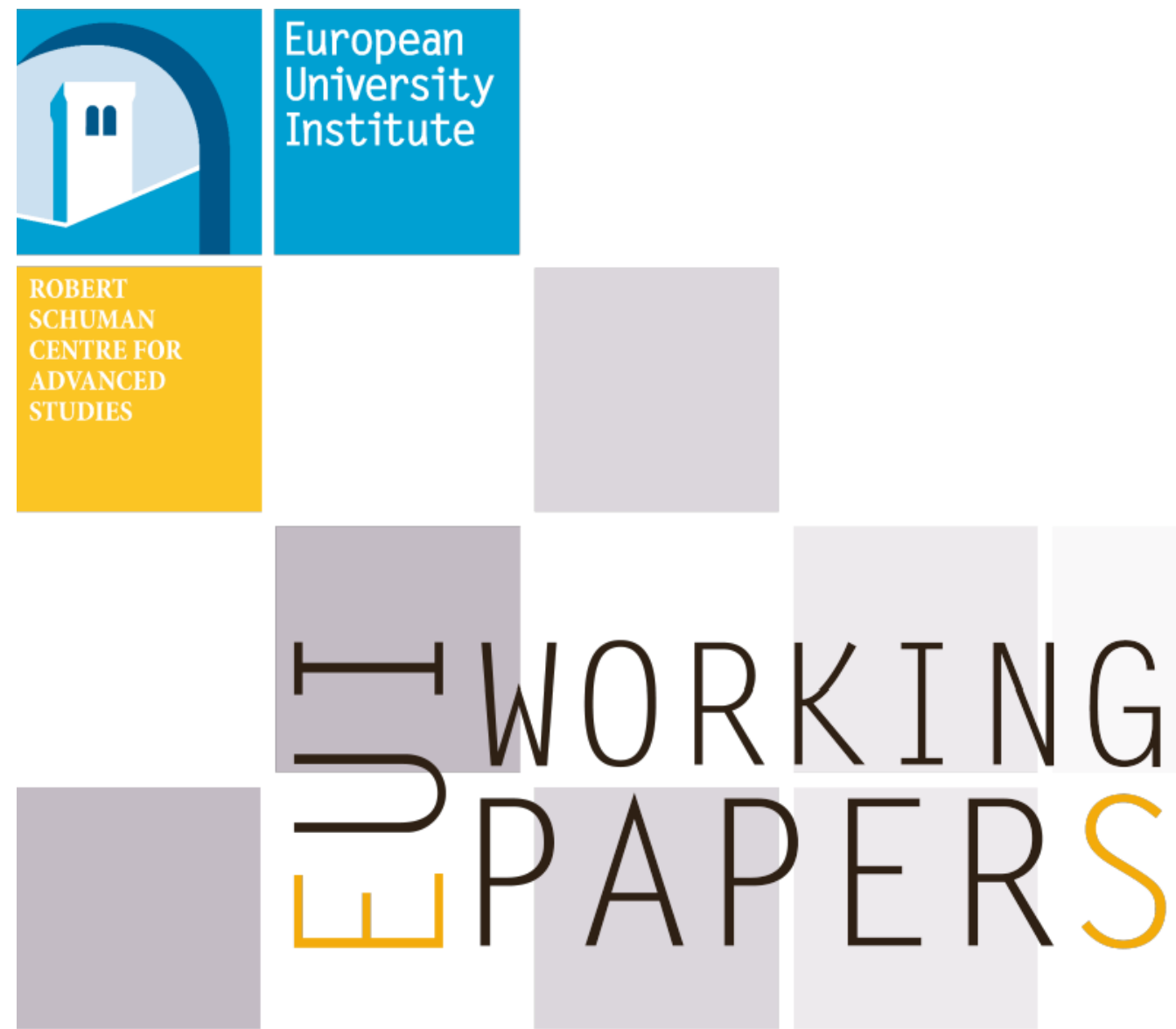

\title{
RSCAS 2017/62
}

Robert Schuman Centre for Advanced Studies Global Governance Programme-287

The Analogue Method Comes Unfastened The Awkward Space Between Market and Non-Market Economies in EC-Fasteners (Article 21.5) 

European University Institute

Robert Schuman Centre for Advanced Studies

Global Governance Programme

The Analogue Method Comes Unfastened - The Awkward Space Between Market and Non-Market Economies in EC-Fasteners (Article 21.5)

Ilaria Espa and Philip I. Levy

EUI Working Paper RSCAS 2017/62 
This text may be downloaded only for personal research purposes. Additional reproduction for other purposes, whether in hard copies or electronically, requires the consent of the author(s), editor(s). If cited or quoted, reference should be made to the full name of the author(s), editor(s), the title, the working paper, or other series, the year and the publisher.

ISSN 1028-3625

(C) Ilaria Espa and Philip I. Levy, 2017

Printed in Italy, December 2017

European University Institute

Badia Fiesolana

I - 50014 San Domenico di Fiesole (FI)

Italy

www.eui.eu/RSCAS/Publications/

www.eui.eu

cadmus.eui.eu 


\section{Robert Schuman Centre for Advanced Studies}

The Robert Schuman Centre for Advanced Studies (RSCAS), created in 1992 and directed by Professor Brigid Laffan, aims to develop inter-disciplinary and comparative research and to promote work on the major issues facing the process of integration and European society.

The Centre is home to a large post-doctoral programme and hosts major research programmes and projects, and a range of working groups and ad hoc initiatives. The research agenda is organised around a set of core themes and is continuously evolving, reflecting the changing agenda of European integration and the expanding membership of the European Union.

Details of the research of the Centre can be found on:

http://www.eui.eu/RSCAS/Research/

Research publications take the form of Working Papers, Policy Papers, Policy Briefs, Distinguished Lectures, Research Project Reports and Books.

Most of these are also available on the RSCAS website:

http://www.eui.eu/RSCAS/Publications/

The EUI and the RSCAS are not responsible for the opinion expressed by the author(s).

\section{The Global Governance Programme at the EUI}

The Global Governance Programme is one of the flagship programmes of the Robert Schuman Centre for Advanced Studies at the European University Institute (EUI). It aims to: build a community of outstanding professors and scholars, produce high quality research and, engage with the world of practice through policy dialogue. At the Global Governance Programme, established and early career scholars research, write on and discuss, within and beyond academia, issues of global governance, focussing on four broad and interdisciplinary areas: European, Transnational and Global Governance; Global Economics; Europe in the World; and Cultural Pluralism.

The Programme also aims to contribute to the fostering of present and future generations of policy and decision makers through its unique executive training programme, the Academy of Global Governance, where theory and "real world" experience meet. At the Academy, executives, policy makers, diplomats, officials, private sector professionals and academics, have the opportunity to meet, share views and debate with leading academics, top-level officials, heads of international organisations and senior executives, on topical issues relating to governance.

For more information: http://globalgovernanceprogramme.eui.eu 



\begin{abstract}
The compliance Appellate Body decision marks the latest twist in the long-running EC-Fasteners dispute. The question before the $\mathrm{AB}$ is whether the European Union complied with earlier rulings on its antidumping procedures. Broadly, the $\mathrm{AB}$ found that the $\mathrm{EU}$ had not, generally ruling in favor of the People's Republic of China. In the process, the AB raised interesting questions about what it means to be a Non-Market Economy (NME) in the WTO. While NME status has traditionally led to large dumping margins, the $\mathrm{AB}$ approach in this case may lessen the consequences for China. Among other things, the case raises the interesting and important question of how pervasive the taint of NME status may be when calculating margins. By allowing for adjustments of certain costs, the AB seems to constrain the more draconian analogue country methodology of calculation.
\end{abstract}

\title{
Keywords
}

WTO Antidumping Agreement, Non-Market Economy, Analogue Country Methodology, EU, China

JEL Classification: P33 



\section{Introduction: Key questions of the case ${ }^{*}$}

Among the most pressing political challenges facing the World Trade Organization is the status of the People's Republic of China for antidumping purposes. In China's Protocol of Accession to the WTO in 2001, it was agreed that for 15 years China could be treated as a Non-Market Economy (NME). (Section 15 (a) of China's Accession Protocol). Though that time period has just passed, China's status remains unresolved. Both the United States and the European Union have indicated an unwillingness to recognize China as a market economy, to China's great consternation. ${ }^{1}$

There is symbolic importance to China's status, but the most significant practical implications concern China's treatment in anti-dumping proceedings. NME status offers greater flexibility for WTO Members importing products from China when it comes to the determination of normal value (AB Report, EC - Fasteners, para. 290). In particular, investigating authorities (IAs) may disregard domestic Chinese domestic prices and costs and choose instead alternative normal value methodologies such as the analogue country methodology, which generally result in higher dumping margins (Vermulst and Meng 2017).

The compliance Appellate Body Report in European Communities - Definitive Anti-Dumping Measures on Certain Iron or Steel Fasteners from China (Article 21.5) (WT/DS397/AB/RW, hereinafter AB Report (Article 21.5, EC - Fasteners), deals directly with what's permissible under the purview of these permissible normal value methodologies and the philosophy that underlies them. The decision, adopted in February 2016, tackles such issues as whether the taint of being an NME pervades an entire economy or is limited to particular segments of that economy. In the context of one standard alternative procedure for dealing with NMEs - turning to an analogue country to estimate "fair value" - it grapples with the balance between the confidentiality interests of the analogue country producers and fair treatment for the NME country producers accused of dumping. And it raises the question of how domestic industry should be defined. All of these elements have the potential to significantly alter the burden associated with the NME label.

This compliance Appellate Body report represents the last step of an elongated litigation process between China and the European Union (EU) dating back to 2009, which deals with the latter's imposition of antidumping (AD) duties on various classes of Chinese fasteners.

In the original proceedings, China challenged certain provisions of the EU antidumping regulation (namely Article 9.5 of the Council Regulation No. 1225/2009) that subjected NME producers failing to meet the so-called 'individual treatment test' to the imposition of country-wide AD duties under Article 6.10 and Article 9.2 ADA. China prevailed in these claims, in that both the Panel and the Appellate Body clarified that the ADA contains no exception to the obligation to calculate individual dumping margins for each sampled exporter when dealing with NMEs (for more details, see Mavroidis and Bown 2013)

A second cluster of claims brought by China in the original proceedings concerned various aspects of the EU measure imposing definitive AD duties on Chinese fasteners (namely, Council Regulation No. 91/2009) under Articles 2, 3, 4, 5, 6, and 12 ADA. In essence, China challenged the way the EU conducted its antidumping investigations both substantively (i.e. by questioning the Commission's determinations regarding standing, the definition of the domestic industry, the product under consideration, dumping and price undercutting, volume and impact of dumped imports, and causation) and procedurally (i.e. by taking issue with the disclosure by the Commission of information relevant

\footnotetext{
We are grateful to our discussant, Edwin Vermulst, and participants at the European University Institute conference. All remaining errors are our own.

1 See Donnan, Hornby, and Beesley 2016.
} 
to the investigation, the way it treated confidential information, and the procedural aspects of individual treatment claims). Here, the original Panel's and Appellate Body's findings were mixed. China prevailed in most procedural claims and in key substantive claims such as those concerning the definition of domestic industry under Article 4.1 and Article 3.1 ADA. Yet, it failed to convince the WTO adjudicators in other instances, including China's claim under the fair comparison requirement established under Article 2.4 ADA. In the AB's view, in particular, China did not provide sufficient evidence to prove that there existed quality differences affecting price comparability between Chinese fasteners and the fasteners produced by Pooja Forge - the sole Indian company that was used as the surrogate to calculate dumping margins by the EU Commission based on the classical analogue country methodology used by the EU in AD investigations against NME producers (see Vermulst and Meng 2017). Pooja Forge plays a big role in this story.

Following the adoption of the Appellate Body report, the EU revised its basic antidumping law, on the one hand (see Regulation (EU) No. 765/2012), and, on the other hand, it initiated a review investigation, which led the Commission to confirm the existence of injurious dumping of fasteners and thus continue with the imposition of definitive duties albeit at revised rates (see Regulation (EU) No 924/2012). The compliance proceedings ultimately covered in the current AB decision arose out of China's claims concerning the conduct of this review investigation by the Commission. Once again, China targeted both substantive and procedural aspects of the Commission's investigation, with its claims revolving around many of the same ADA articles invoked during the original proceedings, namely: (i) Article 6.5, Article 6.4, Article 6.2 and Article 6.1.2 ADA regarding confidential treatment and disclosure of evidence in the Commission's review investigations; (ii) Article 2.4 ADA on the contours of the fair comparison requirement when the analogue country methodology is used against NME producers; (iii) Article 4.1 and Article 3.1 concerning the definition of domestic industry when the major proportion requirement is referred to.

Ultimately, China prevailed in all its claims, including those that were previously rejected at the Panel's stage. Among these, significantly, are China's claims under the fair comparison requirement under Article 2.4 ADA, whose boundaries were for the first time tested with respect to the normal value calculation pursued in AD investigations that involve NME producers when recourse is made to the analogue country methodology. Arguably, this is not what one would have expected based on a plain reading of the provision, which concerns IA's comparisons 'between the export price and the normal value.' Even more so, the Appellate Body interpretation and applications of Article 2.4 ADA claims in this dispute constitute the most interesting and novel among its findings, not only for its meaning in the context of the present dispute but also for its potential systemic implications.

The next section - constituting the bulk of the paper - considers the idea of a middle ground between NME and market economy status. While this is not the way the AB describes its approach, it is arguably the end result. Section 3 briefly looks at the balancing act between the exporting country producers' (China's) right to see the evidence presented against it and the right to confidentiality on the part of firms supplying potentially sensitive data for the normal value determination (in this case, Pooja Forge). Section 4 quickly takes up the argument over a similar balance in the definition of domestic injury, where the practical need to get responses is set against the need to have a representative sample. Section 5 concludes.

\section{Is NME status pervasive, or is its taint limited?}

Given the prolonged litigation in this EC -Fasteners case, many of the issues have been visited repeatedly. One particularly novel and interesting question raised indirectly in the AB Report (Article 21.5, EC - Fasteners) was the nature of NME status. This was not the explicit focus of the case, but the $\mathrm{AB}$ decision had important implications for how NMEs are treated. 
Stepping back from the narrow legal questions at issue here, the NME question, in broad outline, is not terribly difficult. If a country does not have the institutions of a market economy, there are likely to be significant price distortions. As the dumping decision revolves around the comparison, for a given product, of normal values to exported values, the measurement of normal values will be thrown off by the price distortions.

As soon as one delves into the details, however, it rapidly becomes more complicated. Are all reported costs in an NME invalid? Or only some? If an IA turns elsewhere to get more reliable prices, as the European Union did with its analogue country approach, what makes a fair substitute? And how complete should the substitution be? An entire firm? A product? A portion of a product's cost?

The language of the relevant WTO agreements urges fairness in this approach, but provides relatively little guidance on how this fairness is to be achieved. It was into this morass that the $\mathrm{AB}$ plunged.

\section{i. Overview of the question and its context}

China's claims under Article 2.4 ADA related to the Commission's rejection of Chinese fastener producers' requests for adjustment based on differences in taxation, input costs and other costs (access to raw materials, use of self-generated electricity, efficiency in raw material consumption, efficiency in electricity consumption and productivity per employee) and physical characteristics of fasteners. The panel had found that adjusting for such differences would have undermined the European Commission's right to have recourse to the analogue country methodology (Panel Report, EC Fasteners (Article 21.5), para. 7.219; see also para. 7.245), i.e. the classic methodology used by the EU when determining normal value in NMEs.

In ascertaining whether the Commission should have instead warranted such adjustments to Chinese producers, the question that the Appellate Body found itself ultimately confronted with is a question of interpretation of Article 2.4 ADA: can the fair comparison requirement be invoked to request adjustments with respect to the determination of the normal value in and of itself? This is a novel question, to the extent that Article 2.4 ADA formally refers to issues of price comparability 'between normal value and export prices'. ${ }^{2}$ Here, instead, China requests the Commission to adjust for differences in costs between the Chinese (NME) producers under investigation and the analogue country producers within the normal value component of the comparison. Note also, importantly, that China does not challenge the recourse by the Commission to the analogue country methodology as such, nor the use of India as the analogue country producer (AB Report, EC Fasteners (Article 21.5), para. 5.206); it is only interested in introducing an element of flexibility in the normal value determination also when the analogue country methodology is used.

Recall that the analogue country methodology is a widely used practice that has been accepted by the Appellate Body, although it is not explicitly mentioned anywhere in the ADA (and thus, there is no statutory guidance as to how to perform it). Conventionally, its permissibility stems from the second Ad Note to Article VI:1 of the GATT 1994, which is incorporated into Article 2.7 of the AntiDumping Agreement, read in conjunction with Article 2.2 of the Anti-Dumping Agreement. These provisions allow IAs to use a methodology that is not based on a strict comparison with domestic prices or costs in the case of NMEs, i.e. cases where 'special difficulties may exist in determining price comparability'. Also recall that the Appellate Body already clarified in the original proceedings that alternative methodologies employed in investigations involving NMEs, such as the analogue country methodology, can exclusively be used with respect to the normal value side of the comparison

2 While this is a novel legal approach, see below for a formal discussion of whether there is any economic difference between adjusting normal value and adjusting the margin. It is also worth noting that the idea of making adjustments in dumping calculations is not novel. The novelty lies in blending the adjustment approach with the analogue country approach. 
(AB Report, EC Fasteners, para. 485, footnote 460). In line with this acquis, furthermore, Section 15 (a) of the China's Accession Protocol similarly establishes special rules regarding the domestic price aspect of price comparability when Chinese producers are not able to 'clearly show' that marketeconomy conditions prevail in the industry at issue, as was the case of Chinese fasteners producers. The bottom line is that the analogue country methodology may be used as an alternative methodology when domestic prices or costs in China cannot serve as reliable benchmarks to determine normal value (AB Report, EC Fasteners (Article 21.5), para. 5.207).

\title{
ii. Price comparability vs normal value-based adjustment
}

Against this backdrop, the Appellate Body first posited that the fair comparison requirement under Article 2.4 ADA applies 'in all anti-dumping investigations, irrespective of the methodology used to determine normal value' (para. 5.205). It then clarified that Article 2.4 ADA must be read in the context of the second Ad Note to GATT Article VI:1 and Section 15(a) of China's Accession protocol (para. 5.207). This led it to affirm that:

\begin{abstract}
In our view, the investigating authority is not required to adjust for differences in costs between the NME producers under investigation and the analogue country producer where this would lead the investigating authority to adjust back to the costs in the Chinese industry that were found to be distorted. Based on the foregoing, an investigating authority can reject a request for an adjustment if such adjustment would effectively reflect a cost or price that was found to be distorted in the exporting country in the normal value component of the comparison that is contemplated under Article 2.4 of the Anti-Dumping Agreement. (emphasis added, footnote omitted).
\end{abstract}

In drawing this distinction, the Appellate Body did not explicitly exclude that adjustment be warranted for differences in costs between the Chinese (NME) producers under investigation and the analogue country producers within the normal value component of the comparison. Yet, a plain reading of para. 5.207 seemingly prima facie suggests that this could be possible when it refers to the need for IAs to consider whether the requested adjustment reflects ' $a$ cost or price that was found to be distorted in the exporting country.' Thus, arguably, singular cost determinants may be computed into the calculation of the normal value when an analogue country methodology is used.

This interpretation seems consistent with the Appellate Body's application of Article 2.4 ADA in considering China's claims in relation to each of the differences at issue. Here, the Appellate Body rejected the panel's approach, which essentially 'was to find, in general terms and without more, that adjusting for [the] differences [at issue] "would undermine the Commission's right to have recourse to the analogue country methodology" (AB Report, EC-Fasteners (Article 21.5), para. 5.125, citing panel report, para. 7.218). Its premise is arguably that the panel erroneously relied on the EU contention that 'the essence of the EU's analogue country methodology ... is to replace the entire data set of the exporter in the non-market economy country by the data set of a producer in an analogue market economy country, not to replace the distorted costs by market costs' (AB Report, EC Fasteners (Article 21.5), para. 5.206).

In the Appellate Body's view, the panel's approach led it to conclude that the Commission was not required to consider making an adjustment due to the differences at issue solely as a matter of fact, i.e. just because the analogue country methodology was used. Accordingly, it reversed Panel findings and found that the European Commission acted inconsistently with Article 2.4 ADA because it 'failed to assess properly whether the requested adjustment based on [the] differences [at issue, i.e. differences in costs between the Chinese (NME) producers under investigation and the analogue country producers within the normal value component of the comparison.] was warranted, or whether it would have had the effect of reintroducing distorted costs or prices in the normal value component of the comparison' (AB Report, EC-Fasteners (Article 21.5), para. 5.218; see also para. 5.236).

While not going as far as to explaining in detail what the Commission should have done to assess Chinese requests for adjustments on their merits, some insight in this respect can be inferred from what the Appellate Body said on what the European Commission did not do. In particular, the AB said 
the Commission had not checked to see whether price comparability required adjustments. It gave the specific example of comparing energy prices in China and India (see para. 5.233).

Finally, the Appellate Body rejected the panel's acceptance of the distinction between cost differences that pertain to an 'additional step' in the production process, which would affect price comparability, and differences in costs factors incurred by both the analogue country producers and the NME producers. In the Appellate Body view, adjustments are to be made for any differences affecting price comparability on the basis of its approach (see para. 5.234).

\section{A. What are the economic issues involved?}

What would make economic sense here? This is a challenging question in an AD context, since the regime is not constructed to maximize social welfare. ${ }^{3}$ The goal in this discussion, then, will be twofold: from an economic standpoint to assess what the likely effects or implicit assumptions of the procedures may be; and then to ask whether the principles espoused can readily translate into a practicable system.

\section{$i$. The reasoning behind NME status - why the numbers cannot be trusted}

The principal description of a non-market economy in the GATT is found in the second Supplementary Provision to Subparagraph 1 of Article VI, which deals with instances of an exporting country "where the government (a) has a complete or substantially complete monopoly of trade and (b) controls all domestic prices." This clearly marks out an extreme. In such a case, domestic prices could be entirely artificial, particularly if decisions about purchases or sales are not made on the basis of those prices (e.g. if they were made according to governmental dictate). It would be relatively foolish, in such an instance, to carefully compare such artificial numbers against market prices in the import market. The concept of a "normal" or "fair" value in this instance would be difficult.

The Supplementary Provision continues that in such instances, "special difficulties may exist in determining price comparability for the purposes of (determining dumping), and in such cases importing contracting parties may find it necessary to take into account the possibility that a strict comparison with domestic prices in such a country may not always be appropriate."

Before relaxing the extreme assumption that all prices are askew in the NME, we can briefly consider what the economic rationale might be for taking an "analogue country" approach of the sort applied by the EU in this case. There are a couple straightforward (albeit extreme) reference cases to look at, but then turning to more plausible cases gets complicated.

In a first straightforward instance, suppose there was another country that was identical to the NME in its endowments of factors of production and in its technology, but differed by employing marketdetermined prices. In such a case, this market alternative country might provide a ready example of what the price or input costs would be absent government interference in the NME. Note, though, how extreme this case is. It might work in an artificial world with very basic inputs into production and identical technology across countries. But suppose one of the factors of production is human capital. We would expect the accumulation of human capital to respond to the incentive to obtain an education. Thus, even if our NME and this potential surrogate country began with identical endowments, their human capital stocks might quickly diverge.

3 Importing countries typically benefit when they can obtain imports at lower prices. There are known exceptions, such as predatory pricing, but the $\mathrm{AD}$ regime is not targeted at these exceptions. Bown and Mavroidis $2013 \mathrm{fn} 19$ point out that predatory pricing is especially unlikely in the fasteners case, given the large number of firms involved both in China and the EU. 
As a second straightforward instance, suppose that all market producers of a product, say fasteners, had identical costs. This is somewhat less onerous than the earlier assumption. It might occur with common technology and costs largely determined by a common and cheaply tradable input, for example. In this case, given the homogeneity, it would not really matter which surrogate producer or country an investigating authority chose; the same result would emerge. There would be a common cost or price wherever one looked in the market economy world.

We can note in passing that, in the case of fasteners, neither of these cases seem to apply. India, the chosen surrogate country, differs from China in many dimensions. And Bown and Mavroidis 2013 show that India generally has low market share and high unit costs in the market for fasteners.

These two extreme and unlikely cases are the ones in which it is economically sensible and straightforward to substitute a surrogate country's costs. As one moves toward more reasonable circumstances, the procedure becomes more dubious. A great deal of international trade is motivated by differences between countries, either in endowments of factors of production, in production technology, or both.

Turning from the abstract question to the way analogue methodology has been implemented in WTO practice, Dunoff and Moore 2014 address the panel decision in EU-Footwear. They write:

The panel's confirmation that investigating authorities have substantial discretion in selecting an analogue country is potentially troublesome given its importance in determining dumping margins. Anti-dumping scholars and practitioners have long voiced concerns that the selection of the analogue country can be manipulated to produce inflated normal value determinations, in turn leading to inflated dumping margins. (p. 172)

\section{ii. The AB's conception of limited taint}

What if there is a middle ground between undistorted market prices and completely distorted prices? The United States, for example, employs a multi-part test to determine whether a country is a "market economy." 4 The decision by the U.S. Department of Commerce is still a binary one, but the test does suggest that there are degrees of distortions, instances in which a country violates some proper subset of these conditions. For the sake of argument, we can imagine a country in which all prices are free of government intervention except wages. Government-dictated wages, we can imagine, are set at a fraction of the level that would obtain absent government intervention.

Would it then make more economic sense simply to substitute the wage level from another country rather than to substitute all of the costs from the surrogate country? This is the question effectively posed by China in the case. It argues, for example, that India applies taxes on key inputs that China does not apply. Why bring those taxes - a government intervention! - into the estimates of Chinese costs?

This, in fact, is the approach the $\mathrm{AB}$ adopts, as described above. It said that the AD Article 2.4 "Fair Comparison" requirement demanded adjustment to any questionable surrogate comparisons, with a key exception:

(A)n investigating authority can reject a request for an adjustment if such adjustment would effectively reflect a cost or price that was found to be distorted in the exporting country in the normal value component of the comparison that is contemplated under Article 2.4.

The underlying economic idea, then, is that there is a middle ground between an entirely distorted economy and an undistorted economy. There are instances in which an NME (China, in this instance) has certain tainted prices. The $\mathrm{AB}$ is describing an approach which effectively uses Chinese prices

4 "Evaluation of China's Nonmarket Economy Status," U.S.-China Economic and Security Review Commission, Issue Brief, April 18, 2017. Given the lack of any WTO legal text laying out a market test, the European Union has a different list. The point, however, is that each considers multiple factors. 
when they are untainted (e.g. by correcting for differences in surrogate tax practices) and substitutes for Chinese prices when they are tainted.

\section{iii. Under what conditions can costs be sorted this way, into legitimate vs. tainted}

As appealing and efficient as it may sound to excise the bad parts of a cost estimate and retain the good parts, there are some conceptual problems with the idea. It can work cleanly, but only in very special circumstances.

To illustrate, imagine that the production of a certain type of fastener required exactly one unit of an internationally traded input, one hour of machine time and one hour of labor. Suppose, as above, that the only price distortion was in the cost of labor (the wage). In this instance, the substitution of Indian wages for Chinese wages could give a good estimate of what undistorted Chinese costs would be. The key, though, was the fixed production technology.

In a more general setting, a producer might be considering a spectrum of production techniques, from capital-intensive to labor-intensive. The distorted low wage could induce the choice of a laborintensive technique. One can later plug in the "corrected" higher wage, but unless there is a corresponding adjustment to a more capital-intensive technique, there will be an inaccurate estimate of what costs would be, absent the wage distortion.

And, of course, the situation becomes dramatically more complicated when there are multiple distortions. The general case will be that the costs interweave and isolating a single tainted cost will be difficult. But this is a comparison between an ideal, flawless estimate of cost and one that meets practical constraints. Comparing the new practical approach with the old analogue method is another story. Can we say that the new approach is superior? That depends on the metric. It should produce lower dumping margins. If one assumes that NME margins have been excessive, then this is a positive. Because of the difficulty of defining what a "true" cost is for an NME, and because of the way costs interact, it is hard to say whether the new approach is closer.

\section{iv. What is the likely economic impact of the AB's suggested approach?}

It seems highly unlikely that an IA would have a sufficiently sophisticated model of a producer's cost structure to adjust for production method as well as prices. In the case of the wage, above, assuming the (surrogate) high wage paired with a low-wage technique would generally mean an overestimate of the erstwhile undistorted cost in China.

If India were identical to China in all respects other than the wage distortion, this would mean that China could actually be disadvantaged by a partial rather than a complete cost substitution. (India would have the higher wage cost, but the cost-minimizing technique; the partial-substitution constructed cost for China would feature the higher wage cost, but not the cost-minimizing technique).

As noted above, however, it is exceedingly unlikely that India would be identical in all other respects. If there is concern that a surrogate country is selected because of its relatively high costs, and the country facing the dumping examination is selected because of its relatively low costs, then there could be an advantage to limiting the extent to which the high surrogate costs are attributed to the lowcost country.

The question about the advisability of the procedure then becomes whether two wrongs make a right.

The production technique discussion above raises an additional practical challenge stemming from the $\mathrm{AB}$ decision. The $\mathrm{AB}$ called for adjustments except in instances in which the adjustments would effectively bring back a distorted cost from the NME. This presumes the sort of separability described in the extreme, fixed-cost-shares example given above. More generally, as illustrated in the choice of 
technique, one distorted cost can distort other costs. Thus, the question of how narrowly to treat the effects of a distorted cost is not one that has an easy economic answer.

\section{B. How well did the $A B$ do?}

\section{i. Stretching the boundaries of the fair comparison requirement}

The Appellate Body's approach makes clear that recourse to the analogue country methodology cannot serve as a basis to soften the fair comparison requirement (para. 5.205). Rather, it arguably could be interpreted to have the potential to actually expand the scope of Article 2.4 ADA to deal with differences in costs between the Chinese (NME) producers under investigation and the analogue country producers within the normal value component of the comparison. This would certainly introduce an element of novelty that could allow to use Article 2.4 ADA to accommodate for a more flexible (fairer?) determination of normal value for NMEs penalized by a binary application of the analogue country methodology. Yet, in this respect, the Appellate Body is not a model of clarity; many passages of its reasoning remain ambiguous at least. In multiple instances it evokes the possibility that the Chinese producers' requests for adjustment may have been warranted, had the Commission properly run its assessment (recall that such requests were based on alleged differences in costs between the Chinese (NME) producers under investigation and the analogue country producers within the normal value component of the comparison). At the same time, it also repeatedly states that adjustments should be warranted when reflecting 'a difference affecting price comparability' (see, e.g. para. 5.207). In some cases, furthermore, it is really hard to guess whether this reference to price comparability is meant to dispel the doubt as to whether the Appellate Body thinks that Article 2.4 ADA could be used to accommodate claims for adjustments of the normal value cost component only or not. Take for instance para. 5.231:

We recall that the investigating authority is required, under Article 2.4 of the Anti-Dumping Agreement, to make "[d]ue allowance ... in each case, on its merits, for differences which affect price comparability". Where the adjustment would have been otherwise warranted, it is only where it would lead the investigating authority to adjust back to the costs that were found to be distorted that the investigating authority cannot be required to adjust for differences in costs between the NME producers under investigation and the analogue country producer. (footnote omitted).

The last sentence would seemingly imply that in certain cases (namely, when they refer to nondistorted costs or price components of the normal value determination) IAs should adjust for differences in costs between NMEs producers under investigation and the analogue country producer. This interpretation may hold true if one considers that even the second Ad Note to Article VI:1 GATT is arguably not immune from ambiguity with respect to the very concept of 'price comparability'.

While this provision has never been challenged before WTO adjudicators, it has commonly been referred to in WTO case law and the Appellate Body has explained in the original proceedings that, while it refers to difficulties in determining price comparability in general, 'the text of this provision clarified that these difficulties relate exclusively to the normal value of the comparison' (AB Report, $E C-$ Fasteners, para. 285, footnote 408). Otherwise said, one could argue that references to the concept of price comparability do not necessarily exclude ipso facto that adjustment be made for differences arising exclusively from the analogue country methodology used to determine the normal value. This is even more so if one considers that the Appellate Body explicitly stated that Article 2.4 ADA must be read in the context of the second Ad Note to GATT Article VI:1 and Section 15(a) of China's Accession protocol (para. 5.205).

This latter circumstance indicates, however, that the Appellate Body was very careful in tailoring its reasoning to the specific circumstances of the instant dispute, in which the analogue country methodology was used against China as an NME. One could thus argue that, even if the AB approach were to be interpreted as implying that differences arising from the methodology applied for 
establishing the normal value can be challenged under Article 2.4 ADA, such an approach would have short-lived implications for China, given that it could not be treated as a NME after 2016 by virtue of its WTO Accession Protocol. Yet, due to recent developments, particularly the hesitance of the EU in adjusting its regulations pertaining to the determination of normal value for NME countries in antidumping proceedings involving products from China, ${ }^{5}$ the potential of the $\mathrm{AB}$ reasoning to expand the reach of Article 2.4 ADA carries fundamental importance for China. It still remains to be seen whether it could be replicable in the case of NMEs other than China when involved in antidumping proceedings where the analogue country methodology is used. Certainly, the approach designed by the Appellate Body has already generated great concern among big antidumping players, worried that the Appellate Body's approach may adopt an expanded notion of price comparability under Article 2.4 ADA (see Statement by the United States at the Meeting of the WTO Dispute Settlement Body, Geneva, February 12, 2016).

Along the same 'conservative' lines appears the more recent Panel ruling in EU-Biodiesel, which interpreted the AB's approach in EC - Fasteners (Article 21.5) 'as consistent with the general proposition that differences arising from the methodology applied for establishing the normal value cannot, in principle, be challenged under Article 2.4 as "differences affecting price comparability" (Panel Report, EU - Biodiesel, para. 7.304, emphasis added). In the Panel's view, such differences should be primarily governed by Article 2.2 of the Anti-Dumping Agreement (Panel Report, EU Biodiesel, para. 7.301). Importantly, however, the AB explained that 'the Appellate Body report in EC - Fasteners (China) (Article 21.5 - China) does not contain any such "general proposition"' (para. 6.87) and further posited that

6.87. ...we would have serious reservations regarding what the Panel referred to as the "general proposition". The text of Article 2.4 itself makes clear that "[d]ue allowance shall be made in each case, on its merits". This indicates that the need to make due allowance must be assessed in light of the specific circumstances of each case.

At the same time, in the same paragraph the Appellate Body seemingly appears to restrict the potential implications of its understanding of the EC-Fasteners reasoning by saying that 'the reasoning in that report is tailored to the circumstances of that dispute, in which the analogue country methodology was used'.

Irrespective of whether the $\mathrm{AB}$ reasoning is replicable or not in the case of other NMEs involved in antidumping disputes where the analogue country methodology is used, a few considerations seem to suggest that it may be possible for the Appellate Body to stick to the more 'innovative/courageous' interpretation of Article 2.4 ADA in addition to the points identified below: first, this would be consistent with its finding in EC - Fasteners (Article 21.5) that IAs should consider requests for adjustments in light of the differences arising exclusively from the analogue country methodology. It only makes sense to be granted such opportunity if there will be instances in which an adjustment should be warranted in case of differences pertaining to the normal value component of the comparison.

Second, had this not been the case, one fails to see why the Appellate Body did not just dismiss China's claims that Chinese fasteners producers submitted a substantiated request for adjustment under Article 2.4 ADA. The Appellate Body instead rejected the panel's findings that Chinese producers failed to fulfill such requirement. In its view, the panel erroneously relied on the European Commission's determination, which was in turn based on the erroneous premise that adjustments could not be made because certain prices were distorted in China and, thus, corresponding requests could not be substantiated (para. 5.223).

5 See Request for Consultations made by China, European Union - Measures Related to Price Comparison Methodologies, https://www.wto.org/english/tratop_e/dispu_e/cases_e/ds516_e.htm. 
In this respect, the Appellate Body did not provide much guidance as to what are or should be the prerequisites for the producers under investigation to constructively substantiate their requests for adjustment. Yet, it made clear that an improper use of the analogue country methodology creates the wrong premise for finding that a request for adjustment is not substantiated.

Moreover, opting for the more flexible interpretation of Article 2.4 would address an element of fairness inherent to the long-standing debate over the disadvantages that come along NMEs first in antidumping proceedings. In this respect, the attempt of the $\mathrm{AB}$ should be situated in the context of the long-standing debate over China's NME status but it, of course, goes beyond that and potentially affects other NMEs. In this respect, if allowing such flexibility would ultimately be found not to be possible under the purview of Article 2.4 ADA, consideration should be given to granting it under Article 2.2 ADA (yet, one should recall that neither of these articles contains any guidance as to how to perform the analogue country methodology, not to mention how the normal value should be constructed and/or adjusted in such cases). Finally, as explained in the next section, a reading of the $\mathrm{AB}$ reasoning in the sense of excluding that Article 2.4 could accommodate requests for adjustments based on differences arising from the methodology applied for establishing the normal value would not make economic sense.

\section{ii. A Distinction Without a Difference}

Consider the argument that the $\mathrm{AB}$ is requesting changes only in the fair comparison, not in the normal value. While it may be possible to advance this claim legally, it makes little sense from an economic standpoint. To see that, we introduce a small amount of formality.

What is being compared in the fair comparison? IA's calculate a dumping margin $=\mathrm{NV}-\mathrm{EP}$. If this is positive, then there is dumping.

Since we are dealing with the peculiarities of an NME case, we'll set aside any questions about EP and stipulate that this number is clear. Therefore, any interesting activity will either be within NV or will affect the comparison between NV and EP.

Let us assume that $\mathrm{NV}=f\left(x_{1}^{a}, x_{2}^{a}, \quad, x_{n}^{a}\right)$ where the subscripts indicate a cost determinant (labor, imported inputs, rent, etc.) and the superscript a indicates that the cost is being taken from the analogue country (Pooja Forge in India, in our case). Let us suppose that we arbitrarily consider the first component, $\mathrm{x}_{1}$, which we can take to represent input costs. Suppose, further, that the analogue country applies a tax $t$ on input costs which means that $x_{1}^{a}=x_{1}^{*}+t$, where the $*$ superscript indicates the corresponding input cost in the country being investigated (China).

Next, let's assume that a higher input cost leads to a higher normal value. Specifically,

Equation (1) $f\left(x_{1}^{a}, x_{2}^{a}, \quad, x_{n}^{a}\right)=f\left(x_{1}^{*}+t, x_{2}^{a}, \quad, x_{n}^{a}\right)=f\left(x_{1}^{*}, x_{2}^{a}, \quad, x_{n}^{a}\right)+$

This simply says that using the taxed input cost (India) in lieu of the untaxed Chinese cost raises the fair value by some positive number $\alpha$.

Suppose we decide that the inclusion of this tax in the analogue country's cost, $x_{1}^{a}$, is inappropriate. How can the adjustment be made?

Two possibilities:

1. In the calculation of $\mathrm{NV}$, use $\mathrm{NV}^{*}=f\left(x_{1}^{*}, x_{2}^{a}, \quad, x_{n}^{a}\right)$ instead of $\mathrm{NV}=f\left(x_{1}^{a}, x_{2}^{a}, \quad, x_{n}^{a}\right)$. In other words, replace the tax-laden Indian cost with the lower Chinese cost.

2. Don't touch the NV calculation. Instead, when making the dumping comparison, use

Equation (2) NV - $\alpha$ - EP.

From Equation (1), we have that $N V=N^{*}+\alpha$. Substituting this into Equation (2) above shows that the two possibilities are exactly equivalent. 
There is no difference between doing the adjustment inside the NV calculation or applying the corresponding difference when doing the fair comparison, no matter how much the former offends Article 2.4 analogue methodology sensibilities.

And, while we are being formal, so long as we assume that NV (costs) rise monotonically with input costs, i.e. $\frac{N V}{x_{i}}>0, i$ we can also say that for any later "adjustment" $\alpha$, there will be a corresponding input cost $\left(\mathrm{x}_{\mathrm{i}}\right)$ adjustment in the NV determination that would have gotten the same result.

Note, the EU's argument was that any substitution of $x_{i}^{*}$ for $x_{i}^{a}$ would undermine the analogue methodology. That's a logically consistent argument. However, it is impossible to reconcile with the verdict that ultimately an adjustment will be required based on the difference between $x_{i}^{*}$ and $x_{i}^{a}$ for some $\mathrm{i}$ (as in the case of the tax adjustment).

Further, suppose the AB intended to say that NV calculation would stay intact, but that the EU just needed to consider adjustments to the fair comparison in light of the difference between $x_{i}^{*}$ and $x_{i}^{a}$ for some $\mathrm{i}$. This statement is only meaningful if there will be instances in which an adjustment will be required. Otherwise, why criticize the EU for failing to undertake a procedure that will always and inevitably lead to a null result?

Thus, whether or not the $\mathrm{AB}$ intended to alter the calculation of $\mathrm{NV}$ under Article 2.4, this is what it has opened the door to, de facto.

\section{Practical balance - right to see evidence vs. treatment of confidentiality}

When an investigating authority turns to an analogue country, it introduces new players into the case with their own interests. Of necessity, an analogue firm will be a competitor to the firms being investigated for dumping (it can only serve as an analogue if it produces the product). This makes it suitable for comparison, but can also make the firm reluctant to expose sensitive information that could grant its competitors an advantage.

On the other hand, particularly given the concerns discussed above, the responding country will not want simply to take the findings on margins as given; it will want to review the methodology and see whether there were objectionable steps in the calculations.

This, then, sets up the tension. How to balance the right to see evidence against the need for confidentiality. It is exacerbated in a case like EC-Fasteners when there is a single firm used as the analogue source.

The claims addressed by the $\mathrm{AB}$ under this heading take issue with the way the European Commission conducted its $\mathrm{AD}$ investigations and revolve around four main provisions: (i) Article 6.5 ADA, which allows investigating authorities (IAs) to accord confidential treatment to the information provided by the parties upon good cause shown; (ii) Article 6.4 ADA, according to which IAs must provide timely opportunities for all interested parties to see all non-confidential information that is relevant to the presentation of their cases and used by IAs; (iii) Article 6.2 ADA, according to which all interested parties shall have a full opportunity for the defence of their interests throughout the antidumping investigation; and, (iv) Article 6.1.2 ADA, which requires IAs to make non-confidential information presented in writing by one interested party promptly available to other interested parties, was invoked by China. In all claims, China prevailed.

On the subject of confidential treatment of information, the Appellate Body upheld the Panel's findings that the European Commission had gone too far in protecting the confidentiality of the analogue producer, Pooja Forge. Panel and $\mathrm{AB}$ agreed that the Commission violated Article 6.4 by 
failing to disclose information on the characteristics of Pooja Forge's products. And the Appellate Body upheld the panel's finding that the European Commission acted inconsistently with Article 6.2 ADA by failing to accord to all interested parties a full opportunity for the defence of their interests throughout the anti-dumping investigation.

One critical factor in reaching these conclusions was the issue of whether Pooja Forge qualified as an 'interested party' so that the information concerning the list and characteristics of its products be made available to Chinese fasteners producers. The ADA does not contain a precise definition of 'interest party' but includes an illustrative list (Article 6.11). The Appellate Body embraced a pragmatic approach, which looked at how Pooja Forge was treated irrespective of the existence of a formal declaration in the record of the investigation. Against this backdrop, it shed light on the kind of factors that could be relevant for the purposes of determining whether an entity is an 'interested party' within the meaning of Article 6.1.2. Effectively, the fact that the Commission treated Pooja Forge as an interested party was sufficient, even in the absence of any formal declaration of that status (see para. 5.150).

Second, it also clarified that, insofar as confidentiality is concerned, Article 6.1.2 must be read in the context of Article 6.5 so that information that has been accorded confidential treatment by IAs in accordance with the requirements under Article 6.5 is excluded from its scope of application (para. 5.153). In other words, finding a violation of Article 6.5 ADA always determines that the information at issue falls within the scope of the obligation under Article 6.1.2 ADA.

These legal findings tilted heavily in favor of the Chinese in this case. Though the reasoning may seem pragmatic, it does raise some serious questions about whether a viable analogue country method emerges from the decision.

Consider, for example, why any firm would want to serve as an analogue. It clearly takes time and effort to report the data. As a general rule, companies are reluctant to disclose the details of their operations in a way that could potentially aid competitors, and cost data certainly has that potential.

One candidate answer could be that a responding firm has a stake in the outcome of the dumping investigation. It is selected because it is a competitor in the market. If the result of the investigation is a substantial dumping duty against a major competitor, this can benefit the analogue firm. The higher the margin, the greater the potential benefit. This, of course, should be troubling from the perspective of the country under investigation, as it may raise suspicions about the accuracy of the reported data.

In an instance such as the present one in which there is a single reporting firm, the tension is heightened. The firm's numbers will have substantially greater impact on the calculated margin, as compared to a case in which there are multiple reporting firms. This will increase the demand for disclosure. But the fact that there is a single firm means that there is no ability to mask firm-specific data through the use of broader averages, thereby heightening the desire for confidentiality.

A second, closely related issue is one explored carefully by Bown and Mavroidis 2013 - the issue of sampling. The fact that a single Indian firm is chosen to represent a broad Chinese industry dramatically increases the possibility that firm-specific idiosyncrasies can impose substantial costs through increased margin. If anything, this would increase the desire for scrutiny.

A third issue arises exactly because of the question of adjustments discussed above. If there is a presumption that distortions in the analogue country are relevant and may require adjustment, then it becomes that much more important that the country under investigation be able to examine the costs in detail, so as to identify such distortions.

Taken together, these considerations present a difficult balancing act. Make disclosure requirements too onerous for an analogue firm and it will be impossible to persuade such firm to participate. Make the disclosure requirements too lax, and the country under investigation will be unable to ensure that NME producers under investigation are treated properly. 
The fact remains that, in the real word, IAs will just disclose what companies agree to disclose (see Article 6.5.2 ADA, not challenged here), and especially so when the ability to conduct an investigation depends on data provided by one single analogue country producer.

\section{Definition of domestic industry}

A final interesting facet of the $\mathrm{AB}$ decision concerns the definition of domestic industry for injury determinations. What is the burden on an investigating authority to avoid distortion by defining what constitutes a major proportion of total domestic production?

The question before the Appellate Body, in this respect, was whether the European Commission's definition of domestic industry in the review investigations was still inconsistent with Article 4.1 and Article $3.1 \mathrm{ADA}^{6}$ because of the failure to comply with the major proportion requirement. While in the original proceedings the crux of the matter was whether $27 \%$ of total domestic production could constitute a major proportion (with the Commission appropriately linking this percentage to Article 5.4 ADA on sampling), ${ }^{7}$ this time the Appellate Body focused on whether the Commission' process of the domestic industry definition gave rise to a material risk of distortion.

In doing so, the Appellate Body built on its own interpretation of the major proportion requirement in the case of 'fragmented industries with numerous producers' in the original proceedings. Presenting another balancing act, practical constraints might require a lower percentage for 'a major proportion', but the IA had to ensure it did not skew economic data and thereby distort the analysis (para. 412). The lower the percentage of the domestic industry in such cases, the more checking the process of domestic industry definition against risks of distortions becomes important.

The elaboration by the $\mathrm{AB}$ of what constitutes a 'major proportion' under Article 4.1 ADA was not always straightforward. The $\mathrm{AB}$ appears to have refined its opinion on what is a high and a low percentage of the major industry. In the original proceedings, it had posited that major proportion required a 'relatively high proportion' (AB, EC - Fasteners, para. 419) and, although not giving an exact number, it ventured saying that such proportion could be as low as $25 \%$ in the case of fragmented industries (AB, EC - Fasteners, para. 415). ${ }^{8}$ In the present case, it speaks of 'a very high proportion' that substantially reflects the total domestic production and considers that, although such proportion could be lower in special market situations, a 36\% proportion is still too low even in the context of the fragmented fasteners industry (para. 5.313). Yet, here again, the AB neither substantiates the concept of 'fragmented industries', nor goes on to give a percentage threshold.

The latter seems somewhat explained by the second part of its reasoning, according to which failure to satisfy the quantitative component could in principle be remedied by fulfilling the qualitative element of the major industry definition, a chance that the $A B$ seemingly reserves to cases of fragmented industries only. When explaining what this would mean, the $A B$ refers to the burden of IAs to ensure that 'the process of defining the domestic industry does not give rise to a material risk of distortion' (para. 5.303), thus building on its reasoning in the original proceedings. In this respect, it is trenchant in excluding that a self-selection process of the type relied upon by the European Commission could fulfill the qualitative element of the major industry definition, even in special

6 Recall that in the original proceedings the Appellate Body explained that violations of Article 4.1 trigger ipso facto a violation of Article 3.1, inasmuch as an inappropriate definition of the domestic industry would ultimately determine a situation whereby antidumping duties are imposed in disregard of the requirement to base findings on positive evidence. AB Report, EC-Fasteners (China), para. 430

7 For a thorough analysis on this, see Mavroidis and Bown 2013.

8 For a comment on this statement, and on the fuzziness of the concept of ,fragmented industries' see Mavroidis and Bown 2013). 
market situations. This is because the definition of the domestic industry and the selection of producers for the injury sample are distinct steps that should never be confused (para. 5.319).

At the same time, however, it further qualifies its understanding of the qualitative element by emphasizing that selected domestic producers must be representative (para. 5.303). This concept is somewhat misleading to the extent that it may eviscerate the whole point of coming up with the notion of major industry for the purposes of defining the domestic industry. Recall that Article 4.1 gives two options for the definition of the domestic industry: (i) domestic producers as a whole of the like products; (ii) domestic producers whose collective output of the products constitutes a major proportion of the total domestic production. Also note that these two alternative options are juxtaposed under Article 4.1 (AB Report, EC-Fasteners (China), para. 411) and that there should in principle be no hierarchy between them (Panel Report, Russia-Commercial Vehicles, para. 7.09) ${ }^{9}$. In this respect, domestic producers that account for a major proportion of the domestic industry are the domestic industry. Stating that they should be representative of a bigger whole would arguably reduce this to a sampling exercise, creating confusion with the issue of representativeness of the sample of domestic producers in the injury determination, and ultimately introducing a hierarchy between the two methods.

\section{Conclusion}

This compliance report deals with complex issues relating to both procedural and substantive aspects of an antidumping investigations' conduct. While the Appellate Body is careful to underscore the particular factual background that inspired its reasoning, a few findings in this report may ultimately have implications that go beyond what could have been the AB's own original intentions. A case in point is the AB's interpretation of the fair comparison requirement under Article 2.4 ADA. Here, the $\mathrm{AB}$ was at least ambiguous in dealing with China's requests for adjustments within the normal value component of the comparison. On the one hand, it posited that IAs cannot be required to adjust for differences in costs between the NME producers under investigation and the analogue country producer when this would lead to adjusting back to those costs or prices found to be distorted. On the other hand, it did not exclude that adjustments in such cases might be warranted, nor did it rule out that differences arising from the methodology used to determine the normal value could be adjusted under Article 2.4 ADA in the first place.

Arguably, interpreting Article 2.4 ADA as to allow IAs to adjust for differences in costs intervening at the normal value chunk of the dumping margin calculation would be a bit of a stretch when one considers that such article formally refers to issues of price comparability 'between normal value and export prices.' The $\mathrm{AB}$ seems to back away from the potential consequences of expanding the notion of price comparability under Article 2.4 ADA by squarely situating its reasoning in the context of the specific circumstances of that dispute, in which the analogue country methodology was used by the European Commission against China as a NMEs. Yet, does this make its finding any less relevant? It is true that the analogue country methodology is but one of the methodologies used by IAs when dealing with NMEs and that many other important players do not make recourse to it (e.g. the United States). The European Union, however, implements it systematically in antidumping procedures involving those countries that it lists as NMEs, ${ }^{10}$ and the same holds true for other

9 Note also in particular, paragraph 7.13 of the Russia - Commercial Vehicles panel report: "As well, we note that there is no hierarchy between the two possible ways of defining "domestic industry". Accordingly, where an investigating authority properly defines the domestic industry on the basis of "a major proportion", it is no more required to explain or justify either its choice of how it defined domestic industry, or its definition, than if it had defined the domestic industry on the basis of "domestic producers as a whole." for defining the domestic industry."

10

Up until now, China, Vietnam, Kazakhstan, Albania, Armenia, Azerbaijan, Belarus, Georgia, North Korea, Kyrgyzstan, Moldova, Mongolia, Tajikistan, Turkmenistan, and Uzbekistan are considered NMEs in EU antidumping legislation 
important antidumping players (e.g. India). What's more, the dispute comes at the time when the discontinuation of China's NMEs status is by no means set, despite the language introduced in its Accession Protocol to this end, with all that has come with it, including the EU-Price Comparison Methodologies dispute.

In sum, despite the usual dose of ambiguity in the AB's reasoning whenever it engages in 'judicial activism' (Mavroidis and Bown 2013), one should not underestimate the potential (and politically relevant) impact of this report. The report's high level of complexity may well disguise much juicier implications for what it be considered an NME in the WTO legal system, at least for those Chinese producers involved in antidumping investigations carried out by IAs that make recourse to the analogue country methodology.

Before condemning the $\mathrm{AB}$ for judicial activism, it is worth noting the very challenging task before it. The central agreements at issue - the ADA and China's Protocol of Accession - are vague on key points. The $\mathrm{AB}$ was left filling in ample blanks in a politically-charged atmosphere that may endanger the whole WTO system. Whether or not this was the intent of the AB, to the extent that the decision in Article 21.5 EC-Fasteners serves to lessen the burden of NME status, it has the potential to diminish the tension surrounding China's status in the WTO. Though there may be an unpleasant stigma attached to being labeled an NME, the most practical consequence for China has been large dumping margins. To the extent there is new room for making adjustments to margins that minimize the impact of the economically-questionable analogue methodology, this consequence fades. That may be useful in the context of the current stance by both the European Union and the United States that Article 15 of China's Protocol of Accession did not require the granting of Market Economy status after the specified 15-year time period. This diminished burden on China, however, seems unlikely to forestall a politically-charged dispute over China's status.

The parade of politically-charged disputes, including the present case, highlights another systemic lesson - it illustrates the excessive strain put on the Dispute Settlement Mechanism by the prolonged interval without any serious legislative updating at the WTO. China's role in the global economy has changed dramatically since it first joined the WTO. As panels and the Appellate Body turn to the ADA to find guidance on how to deal with issues such as NME status, they repeatedly find blanks that need to be filled. One striking feature of the line of jurisprudence in the EC-Fasteners cases is the extent to which guiding principles need to be pieced together from different snippets of text.

With the disintegration of the Doha Round, there is little prospect for a broad new agreement at the WTO. But the difficult political questions and troubling textual gaps that required judicial improvisation in the EC-Fasteners case demonstrate just how badly such an agreement is needed.

(Contd.)

(European Commission 2016). It should be noted, however, that the EU is in the process of revisiting its antidumping law (Inside US Trade 2017). 


\section{References}

Bown, Chad P and Petros C. Mavroidis (2013). One (Firm) Is Not Enough: A Legal-Economic Analysis of EC-Fasteners. World Trade Review, 12, pp 243-271

Donnan, Shawn, Lucy Hornby, and Arthur Beesley, "China challenges EU and US over market economy status," Financial Times, December 12, 2016.

Dunoff, J., \& Moore, M. (2014). "Footloose and duty-free? Reflections on European Union - AntiDumping Measures on Certain Footwear from China." World Trade Review, 13(2), 149-178. doi:10.1017/S1474745614000056

Inside US Trade (2017). "Official: German minister did not say China should automatically have MES," 30 May 2017.

Statement by the United States at the Meeting of the WTO Dispute Settlement Body, Geneva, February 12, 2016.

U.S.-China Economic and Security Review Commission (2017), "Evaluation of China's Nonmarket Economy Status,” Issue Brief, April 18, 2017

Vermulst, Edwin and Medison Meng (2017). "Dumping and Subsidy Issues in the Renewable Energy Sector." In: T. Cottier and I. Espa (eds.). International Trade in Sustainable Electricity: Regulatory Challenges in International Economic Law (Cambridge: Cambridge University Press), pp. 336-355. 


\section{Author contacts:}

\section{Ilaria Espa}

World Trade Institute

University of Bern

Hallerstrasse 6

CH-3012 Bern

Email: ilaria.espa@wti.org

\section{Philip I. Levy}

Global Economy

The Chicago Council on Global Affairs

Northwestern University Kellogg School of Management

Two Prudential Plaza

180 N Stetson Ave.

Chicago, IL 60601

USA

Email:plevy@thechicagocouncil.org 